\title{
Incidence of gonorrhoea due to penicillinase producing Neisseria gonorrhoeae in Japan 1981-3 and treatment using a new antibiotic combination, BRL25000 (amoxycillin and clavulanic acid)
}

\author{
K OSATO,* H TSUGAMI,* K HARADA, $\dagger$ AND J MARUYAMA $\ddagger$ \\ From the *Osaka Prefectural Bandai Clinic for STD, the †Osaka Prefectural Institute for Public Health Research, \\ and the $\ddagger$ Abenobashi Clinic for STD, Osaka, Japan
}

SUMMARY During the three years $1981-3,134(9 \cdot 1 \%)$ of 1473 patients presenting at our clinics were found to be infected with penicillinase producing strains of Neisseria gonorrhoeae (PPNG).

Minimum inhibitory concentrations (MICs) of benzylpenicillin and ampicillin against these PPNG strains were $8 \mathrm{mg} / \mathrm{l}$ or more, whereas against non-PPNG strains they were consistently $4 \mathrm{mg} / \mathrm{l}$ or less. In contrast, the MIC of BRL25000 (two parts amoxycillin and one part clavulanic acid, the $\beta$ lactamase inhibitor) was $4 \mathrm{mg} / \mathrm{l}$ or less even against PPNG strains. MICs of a number of other drugs commonly used to treat gonorrhoea, such as cephaloridine, cefoxitin, tetracycline, doxycycline, minocycline, kanamycin, and spectinomycin, showed no appreciable differences between non-PPNG and PPNG strains and the MIC of cephaloridine in particular was relatively high.

BRL25000 proved to be very effective in the treatment of PPNG infection and cured all of 121 patients treated. A daily dose of $2 \cdot 25 \mathrm{~g}$, cured 105 patients in two days, 11 patients in three days, four patients in four days, and one patient in five days.

A new rapid diagnostic method for detecting PPNG strains, capable of application at an outpatient clinic and providing a result on the following day, is described.

\section{Introduction}

Since 1976, when the appearance of penicillinase producing Neisseria gonorrhoeae (PPNG) was first reported, $!^{2}$ infections caused by this pathogen spread quickly to many parts of the world. Today almost all countries are faced with the problem of an ever increasing incidence of PPNG strains in patients with gonorrhoea. ${ }^{3}$

The first patient at our clinics diagnosed as having an infection due to a PPNG strain was in $1980 .{ }^{4}$ Since 1981 , the number of patients has tended to increase not only is Osaka, where we are located, but all over the country, which indicates that disease caused by PPNG strains is established in Japan.

In this report we comment on the present prevalence of infection with PPNG strains, based on our treatment experience during the past three years. We

Address for reprints: Dr H Tsugami, The Osaka Prefectural Bandai Clinic for STD, 3-1-45 Bandai Higashi, Sumiyoshi-ku, Osaka 558, Japan

Accepted for publication 12 September 1985 also report the clinical results of treating infections caused by PPNG strains with BRL25000, a formulation containing two parts of amoxycillin and one part of the $\boldsymbol{\beta}$ lactamase inhibitor, clavulanic acid, 5 and compare them with those obtained with amoxycillin and bacampicillin.

\section{Patients and methods}

STUDY POPULATION

We studied patients with gonorrhoea presenting at the Osaka Prefectural Bandai clinic for sexually transmitted diseases (STD) and the Abenobashi clinic for STD during the three years 1981-3.

BACTERIAL EXAMINATION OF NEISSERIA GONORRHOEAE We prepared Gram stained smears of material from the urethra of each man and the urethra and cervix of each woman and examined the smears microscopically for Gram negative diplococci. We cultured the organisms on Isocult (Smith Kline, Sunnyvale, California, USA), which contained modified Thayer-Martin medium. We incubated the 
cultures at $37^{\circ} \mathrm{C}$ for 24 hours in the clinics, during which time a disc (Showa Yakuhin Kako, Tokyo, Japan) containing $30 \mu \mathrm{g}$ ampicillin was applied to the medium to indicate the susceptibility of the organisms to ampicillin. ${ }^{6}$

The Isocult media were then transported to the Osaka Prefectural Institute for Public Health Research, where all isolates were subcultured, Gram stained, tested for oxidase production and carbohydrate degradation capacities, and were identified by coagglutination using Phadebact (Pharmacia, Hounslow, Middlesex, England). Their $B$ lactamase producing capacity was tested by the iodometric and chromogenic cephalosporin methods. ' Isolates that failed to show an inhibition zone, and were therefore not susceptible to penicillin, were B lactamase producing gonococcal strains.

\section{SUSCEPTIBILITY TO ANTIBIOTICS}

We measured the minimum inhibitory concentrations (MICs) of ten antibiotics by the agar plate dilution method. The antibiotics were benzylpenicillin, ampicillin, BRL25000 (amoxycillin two parts plus clavulanic acid one part), cephaloridine, cefoxitin, tetracycline, doxycycline, minocycline, kanamycin, and spectinomycin. We used gonococcal (GC) agar (Difco, Detroit, Michigan, USA) as the basic medium with $1 \%$ IsoVitalex (BBL, Cockeysville, Maryland, USA) added instead of haemoglobin.

Seeded bacterial solutions were adjusted as follows: the baterial strain was incubated at $36^{\circ} \mathrm{C}$ for 18 hours on the basic medium as described above. The bacteria were then suspended in Müller-Hinton broth (Difco) and adjusted to an optical density of 0.3 at $550 \mathrm{~nm}$. The suspension was further diluted tenfold with Müller-Hinton broth to obtain the bacterial inoculum.

TREATMENT AND FOLLOW UP OF PATIENTS INFECTED WITH PPNG STRAINS

All patients with presumptive diagnoses of gonorrhoea (made by identifying typical Gram negative intracellular diplococci on microscopy of

TABLE I Chemotherapy against penicillinase producing Neisseria gonorrhoeae (PPNG)

\begin{tabular}{llll}
\hline Antibiotics & Dose $(\mathrm{g} /$ day $)$ & $\begin{array}{l}\text { Route of } \\
\text { administration }\end{array}$ & $\begin{array}{l}\text { Duration } \\
\text { (days) }\end{array}$ \\
\hline BRL25000* & 2.25 in 3 doses & Oral & $2-5$ \\
Spectinomycin & 2 as a single dose & Intramuscular & 1 \\
Ribostamycin & 1 as a single dose & Intramuscular & 2 \\
Minocycline & 0.3 in 3 doses & Oral & 5
\end{tabular}

*BRL25000 administered as $375 \mathrm{mg}$ tablets containing amoxycillin $250 \mathrm{mg}$ and clavulanic acid $125 \mathrm{mg}$.

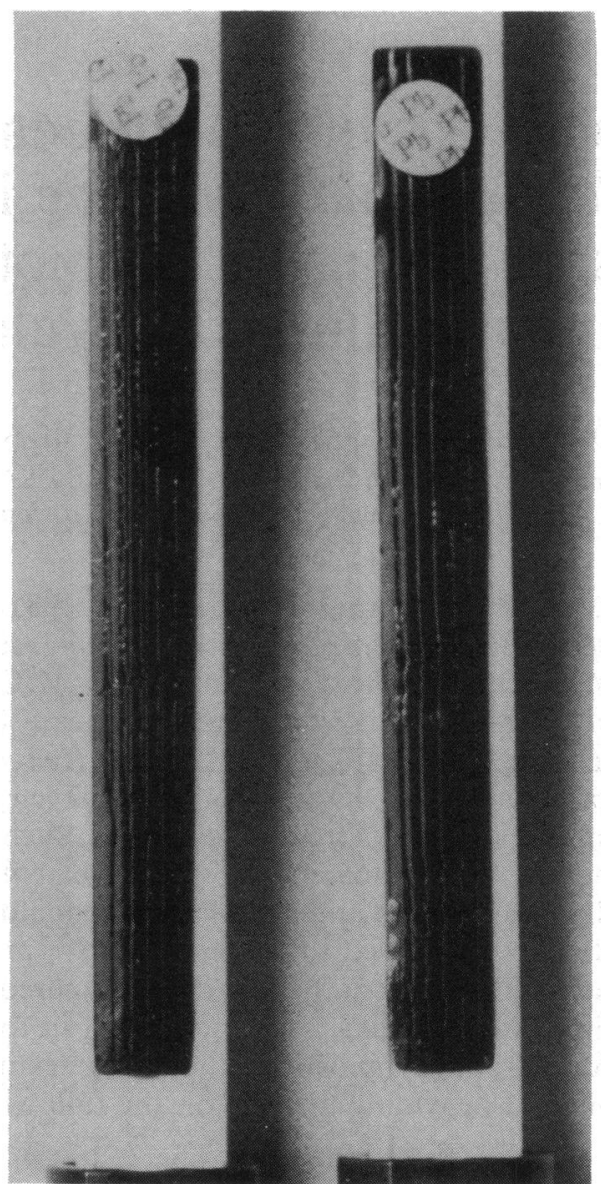

FIG 1 Upper stick - gonococcus not susceptible to penicillin (PPNG strain) showing no inhibition zone from the disc. Lower stick - gonococcus susceptible to penicillin showing about 20 $\mathrm{mm}$ inhibition zone from the disc.

their smears), except those hypersensitive to penicillins, were given $0.5 \mathrm{~g}$ amoxycillin or bacampicillin by mouth three times a day for three to five days.

Patients were advised to return if they did not show any clinical improvement by the following day. After confirmation that gonococcus like organisms were still present in Gram stained smears, their treatment was changed to one of the alternatives listed in table I. Isolates from these patients failed to show an inhibition zone by the disc test (fig 1) by the following day, whereas penicillin sensitive gonococci showed an inhibition zone of $20-30 \mathrm{~mm}$ by that time.

We asked patients to return to the clinics three to seven days after treatment for the tests of cure, when we performed Gram staining of smears for microscopy and culture as at the initial examination. 
No of patients with gonorrhoea Infections ( $\%$ of total) caused by PPNG strains

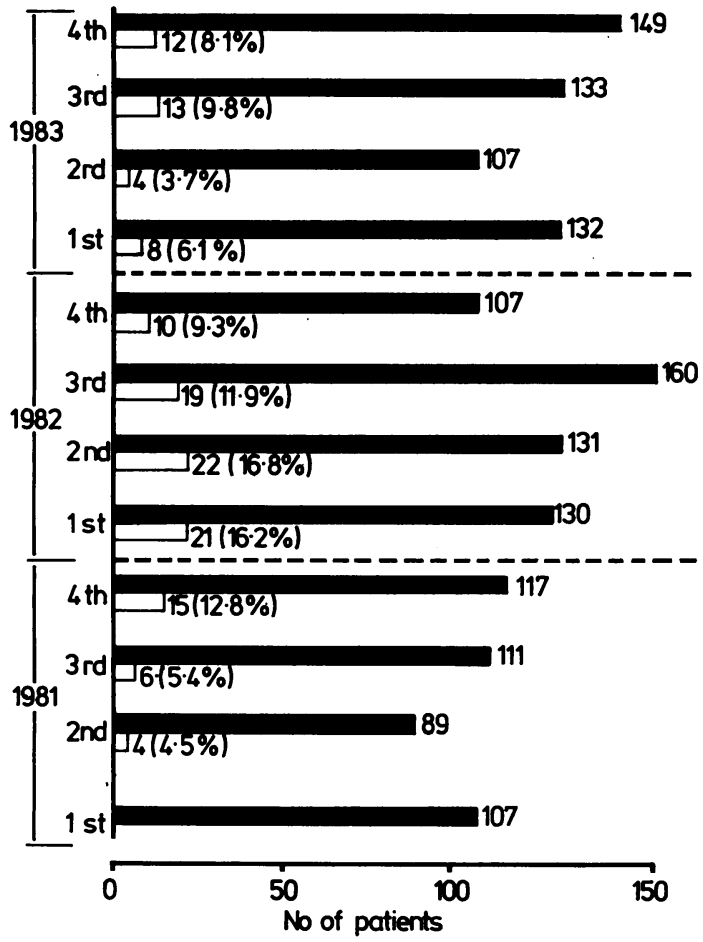

FIG 2 Patients presenting with gonorrhoea in each quarter of 1981-3 and proportion of them infected with penicillinase producing Neisseria gonorrhoeae (PPNG strains).

\section{Results}

INCIDENCE OF INFECTIONS CAUSED BY PPNG STRAINS Figure 2 shows the total number of patients with gonorrhoea and those with infections due to PPNG strains who presented during the past three years. In 1981424 patients cases presented, including $25(5.9 \%)$ infected with PPNG strains. In 1982 the total number was 528, including $72(13.6 \%)$ infected with PPNG strains, whereas in 1983 we treated 521 patients including $37(7 \cdot 1 \%)$ infected with PPNG strains.

In the three years we saw a total of 1473 patients (1381 men and 92 women), of whom $134(9 \cdot 1 \%)(120$ $(89.6 \%)$ men and $14(10.4 \%)$ women) were infected with PPNG strains. The incidence of PPNG strains in men was $8.7 \%(120 / 1381)$ compared with $15.2 \%$ $(14 / 92)$ in women.

All men infected with PPNG strains presented with urethritis, and they included one case complicated with seminal vesiculitis and three cases complicated with abscesses of the glands of Tyson. Women infected with PPNG strains included 10 with uncomplicated cervicitis, three with endometritis, and one with salpingitis.

SUSCEPTIBILITY (MIC) OF ISOLATES TO ANTIBIOTICS Table II shows the MICs of the 10 antibiotics against 123 PPNG and 199 non-PPNG strains. MICs of benzylpenicillin and ampicillin against non-PPNG strains were all $4 \mathrm{mg} / 1$ or less, whereas those against PPNG strains were all $8 \mathrm{mg} / 1$ or more. The MICs were thus clearly divided into two distinct ranges against non-PPNG and PPNG strains. Of the 199 non-PPNG strains, $88(44.2 \%)$ were inhibited by $1 \mathrm{mg} / 1$ or more benzylpenicillin and $77(38.7 \%)$ by the same concentrations of ampicillin.

MICs of BRL25000, a combination of amoxycillin and clavulanic acid, for non-PPNG strains were all 4 $\mathrm{mg} / \mathrm{l}$ or less, which were similar to those of the above two penicillins. MICs of BRL25000 for PPNG strains, however, differed considerably from those of benzylpenicillin and ampicillin, being $4 \mathrm{mg} / \mathrm{l}$ or less. Of the 123 PPNG strains tested against BRL2500, 56 $(45 \cdot 5 \%)$ were susceptible to $4 \mathrm{mg} / \mathrm{l}$ and another 56 $(45.5 \%)$ to $2 \mathrm{mg} / \mathrm{l}$, together accounting for 112 $(91 \cdot 1 \%)$ of these strains. Nevertheless, the MICs of BRL25000 for PPNG strains were still two to four times higher than for non-PPNG strains.

For cephaloridine, a first generation cephalosporin unstable to B lactamases, the most common MIC for the 199 PPNG strains was $16 \mathrm{mg} / \mathrm{l}$ and all MICs were 4 $\mathrm{mg} / 1$ or more. for non-PPNG strains the peak was 8 $\mathrm{mg} / \mathrm{l}$, and $93(46.7 \%)$ of the strains were susceptible to $8 \mathrm{mg} / \mathrm{l}$ or more. About half of the non-PPNG strains showed MICs as high as those of benzylpenicillin and ampicillin for PPNG strains.

With cefoxitin, a second generation cephamycin highly stable to B lactamases, MICs for PPNG and non-PPNG strains were all $4 \mathrm{mg} / 1$ or less, and similar proportions of non-PPNG (136/199 (68.3\%)) and PPNG (106/199 (86.2\%)) strains were susceptible to 1 $\mathrm{mg} / 1$ or more.

Among the tetracyclines, the peak MIC for both non-PPNG and PPNG strains was $4 \mathrm{mg} / 1$ for tetracycline, $2 \mathrm{mg} / 1$ for doxycycline, and $1 \mathrm{mg} / 1$ for minocycline. Of the 199 non-PPNG strains, 108 $(54 \cdot 3 \%)$ were susceptible to $1 \mathrm{mg} / \mathrm{l}$ or more tetracycline. Corresponding figures for doxycycline were $79(56 \cdot 8 \%)$ and for minocycline were $22(15 \cdot 8 \%)$. MICs of $1 \mathrm{mg} / 1$ or more of the three tetracyclines were observed in $79.7 \%(98 / 123), 79.2 \%(76 / 96)$, and $24.0 \%$ (23/96), respectively of PPNG strains.

The aminoglycosides, kanamycin and spectinomycin, had MICs of $16 \mathrm{mg} / 1$ for most non-PPNG and PPNG strains. MICs of kanamycin for the 199 non-PPNG strains were $16 \mathrm{mg} / 1$ or more for $181(91 \%)$ strains, whereas those for PPNG strains were that high 
TABLE II Minimum inhibitory concentrations (MICs) of 10 antibiotics against 322 isolates of Neisseria gonorrhoeae obtained in $1981-3$ (inocula $10^{8}$ cells $/ \mathrm{ml}$ )

\begin{tabular}{|c|c|c|c|c|c|c|c|c|c|c|c|c|c|}
\hline \multirow[b]{2}{*}{ Antibiotics } & \multirow[b]{2}{*}{ Strains } & \multicolumn{12}{|c|}{ No of strains with MICs $(\mathrm{mg} / \mathrm{l})$ of: } \\
\hline & & $\leqslant 0.06$ & 0.13 & 0.25 & 0.5 & 1 & 2 & 4 & 8 & 16 & 32 & $\geqslant 64$ & Total \\
\hline Benzylpenicillin & $\begin{array}{l}\text { Non-PPNG } \\
\text { PPNG }\end{array}$ & 37 & 29 & 19 & 26 & 48 & 27 & 13 & 9 & $24^{\circ}$ & 63 & 27 & $\begin{array}{l}119 \\
123\end{array}$ \\
\hline Ampicillin & $\begin{array}{l}\text { Non-PPNG } \\
\text { PPNG }\end{array}$ & 11 & 36 & 33 & 42 & 51 & 22 & 4 & 4 & 9 & 30 & 80 & $\begin{array}{l}199 \\
123\end{array}$ \\
\hline BRL25000* & $\begin{array}{l}\text { Non-PPNG } \\
\text { PPNG }\end{array}$ & 1 & 5 & $\begin{array}{r}21 \\
1\end{array}$ & $\begin{array}{r}50 \\
5\end{array}$ & $\begin{array}{r}52 \\
5\end{array}$ & $\begin{array}{l}22 \\
56\end{array}$ & $\begin{array}{r}1 \\
56\end{array}$ & & & & & $\begin{array}{l}152 \\
123\end{array}$ \\
\hline Cephaloridine & $\begin{array}{l}\text { Non-PPNG } \\
\text { PPNG }\end{array}$ & & & & & 20 & 30 & $\begin{array}{l}56 \\
12\end{array}$ & $\begin{array}{l}61 \\
28\end{array}$ & $\begin{array}{l}31 \\
50\end{array}$ & $\begin{array}{r}1 \\
32\end{array}$ & 1 & $\begin{array}{l}199 \\
123\end{array}$ \\
\hline Cefoxitin & $\begin{array}{l}\text { Non-PPNG } \\
\text { PPNG }\end{array}$ & 3 & 4 & $\begin{array}{r}27 \\
1\end{array}$ & $\begin{array}{l}29 \\
16\end{array}$ & $\begin{array}{l}75 \\
53\end{array}$ & $\begin{array}{l}54 \\
53\end{array}$ & 7 & & & & & $\begin{array}{l}199 \\
123\end{array}$ \\
\hline Tetracycline & $\begin{array}{l}\text { Non-PPNG } \\
\text { PPNG }\end{array}$ & 2 & 22 & $\begin{array}{r}10 \\
3\end{array}$ & $\begin{array}{l}57 \\
22\end{array}$ & $\begin{array}{l}37 \\
35\end{array}$ & $\begin{array}{l}69 \\
59\end{array}$ & $\begin{array}{l}2 \\
4\end{array}$ & & & & & $\begin{array}{l}199 \\
123\end{array}$ \\
\hline Doxycycline & $\begin{array}{l}\text { Non-PPNG } \\
\text { PPNG }\end{array}$ & 5 & $\begin{array}{r}18 \\
2\end{array}$ & $\begin{array}{r}14 \\
7\end{array}$ & $\begin{array}{l}23 \\
11\end{array}$ & $\begin{array}{l}39 \\
17\end{array}$ & $\begin{array}{l}40 \\
59\end{array}$ & & & & & & $\begin{array}{r}139 \\
96\end{array}$ \\
\hline Minocycline & $\begin{array}{l}\text { Non-PPNG } \\
\text { PPNG }\end{array}$ & $\begin{array}{r}24 \\
3\end{array}$ & $\begin{array}{l}16 \\
10\end{array}$ & $\begin{array}{l}37 \\
14\end{array}$ & $\begin{array}{l}40 \\
46\end{array}$ & $\begin{array}{l}22 \\
23\end{array}$ & & & & & & & $\begin{array}{r}139 \\
96\end{array}$ \\
\hline Kanamycin & $\begin{array}{l}\text { Non-PPNG } \\
\text { PNG }\end{array}$ & & & & & & 1 & $\begin{array}{l}5 \\
2\end{array}$ & $\begin{array}{l}12 \\
20\end{array}$ & $\begin{array}{r}164 \\
98\end{array}$ & $\begin{array}{r}17 \\
3\end{array}$ & & $\begin{array}{l}199 \\
123\end{array}$ \\
\hline Spectinomycin & $\begin{array}{l}\text { Non-PPNG } \\
\text { PPNG }\end{array}$ & & & & & & & $\begin{array}{l}6 \\
2\end{array}$ & $\begin{array}{l}82 \\
25\end{array}$ & $\begin{array}{r}101 \\
87\end{array}$ & $\begin{array}{r}10 \\
9\end{array}$ & & $\begin{array}{l}199 \\
123\end{array}$ \\
\hline
\end{tabular}

* BRL25000 = amoxicillin two parts and clavulanic acid one part.

for $101(82.1 \%)$ strains. MICs of spectinomycin against non-PPNG strains were $16 \mathrm{mg} / 1$ or more for $55.8 \%(111 / 199)$ of strains compared with $78 \%$ $(96 / 123)$ of PPNG strains.

TREATMENT OF PATIENTS WITH INFECTIONS DUE TO PPNG STRAINS

From a total of 1473 patients, 106 were excluded on the basis of possible hypersensitivity to penicillins. Of the remaining 1367,798 were treated with amoxycillin and 569 with bacampicillin at a dose of $0.5 \mathrm{~g}$ orally three times a day for three to five days.

Clinical evaluation in the 798 patients receiving amoxycillin showed a poor response in $88(11 \%)$, comprising 76 infected with PPNG and 12 with nonPPNG strains. In the 569 cases treated with bacampicillin, $69(12 \cdot 1 \%)(58$ infected with PPNG and 11 with non-PPNG strains) showed a poor response.

Patients with infections due to PPNG strains who had failed to respond to the first choice penicillin were treated with BRL25000 (121 patients), spectinomycin (10), ribostamycin (two), or minocycline (one). Table I shows the doses and routes of administration of these drugs.

Of the patients treated with BRL25000, men with uncomplicated urethritis were all completely cured after two days. One suffered a relapse because he arbitrarily stopped taking the tablets after he had taken six. A complete cure was effected when he took six tablets a day for two days. In three men with complicated urethritis, the urethritis was cured after they had taken six tablets a day for two days, but a patient with seminal vesiculitis had to be treated for three days and two with abscesses of the glands of Tyson had to be treated for three and five days, respectively, to be completely cured. Cervicitis resolved in each woman within three days of treatment; endometritis and salpingitis resolved within four days after the start of treatment.

Patients treated with spectinomycin, ribostamycin, or minocycline were also all cured. In one patient with an abscess of the glands of Tyson, urethritis was cured by bacampicillin, but the abscess opened spontaneously seven days later and PPNG strains were identified in the exudate; cure was achieved by treatment with spectinomycin. We did not find any infections due to the recently reported spectinomycin resistant PPNG strains. ${ }^{89}$

\section{SIDE EFFECTS OF BRL25000}

Of the 121 patients infected with PPNG strains who were treated by oral administration of BRL 25000 for two to five days, two reported having headache, one epigastric pain, five nausea, and one diarrhoea. All these side effects were mild and did not necessitate withdrawal of the treatment. 


\section{Discussion}

Gonorrhoea due to PPNG strains was first reported in Japan in $1979,{ }^{10}$ and this was followed by a rapid succession of outbreaks. ${ }^{11}$ According to our statistics for the past three years, one in every ten patients with gonorrhoea is now infected with a PPNG strain. From the characteristic of their plasmids, the PPNG strains in Japan are of the Far Eastern type, which originated from South East Asia. ${ }^{12}$

Thus it is now essential for us to know as soon as possible whether the causal gonococci are PPNG strains or not. We have therefore devised a way of identifying PPNG strains within 24 hours of a patient presenting. The method can be used simply, quickly, and at a low cost even at clinics with minimum diagnostic facilities. It was devised to investigate the susceptibility of clinical isolates to penicillins. Later, however, all strains shown to be non-sensitive by this method were also identified as producing $B$ lactamase, and we therefore developed it as a reliable method for detecting PPNG strains. ${ }^{6}$

An interesting phenomenon recently came to our notice using this method. Several colonies that appeared within the inhibition zone were found to be PPNG strains and a few PPNG colonies were also found outside the inhibition zone. Nevertheless, the patient concerned was cured with amoxycillin. Though this was probably a case of mixed infection with non-PPNG and PPNG strains, no relapse occurred, possibly because there were very few PPNG colonies. As we will have to pay more attention to relapse due to mixed infections like this, our rapid diagnostic method will no doubt prove useful for their early detection.

In the treatment of gonorrhoea, treatment guidelines issued by the Centers for Disease Control (CDC) are being followed extensively worldwide. The basic treatments recommended are a single large dose of penicillin by mouth or injection. The usual treatment regimen for gonorrhoea adopted in Japan, however, is penicillin given orally in divided doses for several days. At our clinics we give $0.5 \mathrm{~g}$ amoxycillin or bacampicillin orally three times a day for several days, with very satisfactory results. Oral medication is also advisable for safety as it avoids the risk of shock sometimes associated with parenteral penicillins.

For treating PPNG infections, we were offered an opportunity to use BRL25000, ${ }^{14}$ a combination of amoxycillin and the $B$ lactamase inhibitor, clavulanic acid. ${ }^{15}$ The drug was administered orally to patients in the usual way. BRL25000 was used in the treatment of 121 out of 134 patients infected with PPNG strains and satisfactory results were obtained in all of them. Thus we have found this drug to be excellent for oral use against PPNG strains. The total doses used in treating urethritis in men were $3 \mathrm{~g}$ amoxycillin and $1.5 \mathrm{~g}$ clavulanic acid. Latif $e t$ al reported that they used $3 \mathrm{~g}$ amoxycillin and $250 \mathrm{mg}$ clavulanic acid in treating gonococcal urethritis in men, but found a failure rate of $9 \cdot 4 \%(6 / 64) .{ }^{16}$ Their study included five patients infected with PPNG strains, but it is not known whether they were included in the failures. At any rate, their results differ from our findings. In another study, Lim et al used $3 \mathrm{~g}$ amoxycillin and $250 \mathrm{mg}$ clavulanic acid orally for two days and obtained far better results than with the same dosage for only one day. ${ }^{17}$ The incomplete cures achieved in these studies may be attributable to the fact that the ratio between amoxycillin and clavulanic acid was not in the optimum range ${ }^{18}$ or to administration of the drug as a single oral dose.

\section{References}

1. Philips I. $\beta$-lactamase-producing penicillin-resistant gonococci. Lancet 1976;ii:656-7.

2. Ashford WA, Golash RG, Hemming VG. Penicillinaseproducing Neisseria gonorrhoeae. Lancet 1976;ii:657-8.

3. Centers for Disease Control. Global distribution of penicillinase-producing Neisseria gonorrhoeae (PPNG) MMWR 1982;31:1-3.

4. Tsugami $\mathbf{H}$, Osato $\mathbf{K}$, Maruyama J, Harada $K$. Incidence of patients with penicillin-resistant gonococci. Japanese Joumal of Venereal Diseases 1982;63:5-10.

5. Reading C, M Cole. Clavulanic acid: a beta-lactamaseinhibiting beta-lactam from Streptomyces clavuligerus. Antimicrob Agents Chemother 1977;11:852-7.

6. Tsugami $H$, Osato $K$. Bacteriological tests for sexually transmitted diseases. Journal of Medical Technology (Japan) 1984;28:124-9.

7. Anonymous. Techniques for the detection of $\boldsymbol{\beta}$-lactamaseproducing strains of Neisseria gonorrhoeae. WHO Tech Rep Ser 1978;616137-42.

8. Ashford WA, Potts Dw, Adams HJU, et al. Spectinomycinresistant penicillinase-producing Neisseria gonorrhoea. Lancet 1981;ii:1035-7.

9. Centers forDisease Control. Spectinomycin-resistant penicillinase-producing Neisseria gonorrhoeae, California. MMWR 1981;30:221-2.

10. Onoda Y, Mitsui I, Ohara Y, Yamai S, Miyamoto Y, Ashizawa $M$. Initial isolation of a strain of Neisseria gonorrhoeae producing $\beta$-lactamase (PPNG) in Japan. Chemotherapy (Tokyo) 1979;27:265-8.

11. Yoshida S, Urabe S, Mizuguchi Y. Antibiotic sensitivity patterns of penicillinase-positive and penicillinase-negative strains of Neisseria gonorrhoeae isolated in Fukuoka, Japan. British Journal of Venereal Diseases 1982;58:305-7.

12. Kano A, Plasmid of $\beta$-lactamase-producing gonococci. Nippon Saikingaku Zasshi 1980;35:99-103.

13. Centers for Disease Control. Sexually transmitted diseases treatment guidelines 1982. MMWR 1982;31:33-60.

14. Okazaki T, Machida T, Onodera S. Fundamental and clinical studies on BRL25000 (clavulanic acid-amoxicillin) in gonorrhea urethritis. Chemotherapy (Tokyo) 1982;30(suppl 2):413-7.

15. Miller $\mathbf{J M}$, Baker $\mathbf{C N}$, Thornburg $C$. Inhibition of betalactamase in Neisseria gonorrhoeae by sodium clavulanate. Antimicrob Agents Chemother 1978;14:794-6.

16. Latif AS, Sithole J, Bvumbe S, Gumbo B, Kawemba M, Summers RS. Treating gonococcal urethritis in men: oral amoxycillin potentiated by clavulanate compared with intramuscular procaine penicillin. British Journal of Venereal Diseases 1984;60:29-30.

17. Lim KB, Rajan VS, Giam YC, Lui EO, Sng EH, Yeo KL. Two dose Augmentin treatment of acute gonorrhoea in men. British Joumal of Venereal Diseases 1984;60:161-3.

18. Nakazawa H, Matsuura M, Mitsuhashi S. Beta-lactamase inhibitory effect of clavulanic acid and antibacterial activity of BRL25000 (clavulanic acid-amoxicillin). Chemotherapy (Tokyo) 1982;30(suppl 2):1-10. 